\title{
Kappa-Opioid Agonist U69593 Potentiates Locomotor Sensitization to the D2/D3 Agonist Quinpirole: Pre- and Postsynaptic Mechanisms
}

\author{
Melissa L Perreault', Dawn Graham', Liane Bisnaire', Jennifer Simms', Scott Hayton' and \\ Henry Szechtman*, \\ 'Department of Psychiatry and Behavioural Neurosciences, McMaster University, Hamilton, ON, Canada
}

\begin{abstract}
To assess whether the development and expression of behavioral sensitization to the dopamine D2/D3 agonist quinpirole (QNP) is influenced by coadministration of the kappa opioid receptor agonist U69593, rats received every 3-4 days for a total of 10 treatments an injection of $\mathrm{U} 69593(0.3 \mathrm{mg} / \mathrm{kg})$ together with an injection of either a postsynaptic $(0.5 \mathrm{mg} / \mathrm{kg})$ or a presynaptic dose of QNP (0.05 mg/ $\mathrm{kg}$ ); locomotor activity was measured after each treatment. Control rats were injected as appropriate with QNP, U69593, and vehicle/ saline. Following chronic treatment, dose-response profiles to QNP were obtained to assess the expression of sensitization; the effect of U69593 on locomotor activity in animals already sensitized to QNP was also assessed. Results showed that cotreatment of U69593 with a postsynaptic dose of QNP doubled the speed and magnitude of sensitization to QNP, while U69593 cotreatment with a presynaptic dose of QNP switched the effects of QNP from locomotor depression to locomotor sensitization. However, U69593 cotreatment with a presynaptic dose of QNP changed a different set of measures of sensitization than did cotreatment with a postsynaptic dose of the dopamine agonist. Together, findings suggest that sensitization to QNP is not a unitary phenomenon but has components that are relatively independent, mediated by distinct pre- and postsynaptic mechanisms and modulated by kappa receptor activity.

Neuropsychopharmacology (2006) 3 I, 1967-198I. doi:I0.1038/sj.npp. I 300938; published online 12 October 2005
\end{abstract}

Keywords: kappa-opioid dopamine receptor coactivation; U69593; chronic drug treatment; components of sensitization; oppositional DI-D2 interaction; dose-response curves

\section{INTRODUCTION}

Repeated exposure to a dopamine stimulant drug such as cocaine, amphetamine, or quinpirole (QNP) produces a progressive augmentation of behavioral responses to the drug, a phenomenon known as behavioral sensitization (Robinson and Becker, 1986). Behavioral sensitization is of much interest because of its potential relevance to several human pathologies ranging from drug addiction to schizophrenia (Kalivas and Stewart, 1991; Koob and Le Moal, 1997; Robinson and Becker, 1986; Segal and Schuckit, 1983) and obsessive-compulsive disorder (Eilam and Szechtman, 2005; Szechtman et al, 1998, 2001; Tizabi et al, 2002). Responses that sensitize with chronic drug treatment may

\footnotetext{
*Correspondence: Dr H Szechtman, Department of Psychiatry and Behavioural Neurosciences, McMaster University, 1200 Main Street West, Health Science Centre, Room 4N82, Hamilton, Ontario, Canada L8N 3Z5, Tel: + I 905525 9|40×24012; Fax: + I 905522 8804; E-mail: szechtma@mcmaster.ca

Received 29 April 2005; revised 27 July 2005; accepted 7 September 2005

Online publication: 13 September 2005 at http://www.acnp.org/ citations/Npp09| 305050277/default.pdf
}

include locomotion, sniffing, licking, or biting. The alterations in behavior, especially locomotor behavior, can be quite complex, but most often they involve an exacerbation of specific features of the behavioral response to an acute drug administration.

The acute effects of dopamine agonists on locomotion are generally biphasic, with locomotor depression followed by locomotor excitation (Harkin et al, 2000; Kelsey and Carlezon Jr, 2002; Van Hartesveldt et al, 1992, 1994). It had been proposed that the depressive effects of dopamine agonists probably reflect stimulation of presynaptic dopamine receptors (Clark et al, 1985; Richtand et al, 2001; Starr and Starr, 1986). During the course of repeated administrations, the depressive effects of dopaminomimetic drugs diminish and the excitatory locomotor responses become stronger, occur sooner, and to lower doses of the drug (Segal et al, 1980; Szechtman et al, 1994b; Szumlinski et al, 1997). One hypothesis suggests that sensitization reflects a tolerance of the drug depressive effects (Baker and Tiffany, 1985; Hinson and Siegel, 1983) possibly due to the subsensitivity of presynaptic dopamine receptors (Antelman and Chiodo, 1983; Castro et al, 1985; Muller and Seeman, 1979; Richtand et al, 2001). However, this hypothesis 
is likely in need of refinement, as we have recently shown that tolerance to presynaptic doses of the D2/D3 agonist QNP does not develop, nor does locomotor sensitization as indexed by excitatory doses of QNP (Lomanowska et al, 2004). In contrast, a competing hypothesis suggests that chronic treatment with a dopamine agonist does not produce tolerance, but augments the excitatory effects of the drug such that the inhibitory effects are occluded by the reduced latency to excitation (Einat et al, 1996).

One approach to investigate the mechanisms underlying behavioral sensitization involves manipulations of the mesolimbic dopamine pathway, a pathway involved in behavioral sensitization (Kalivas and Stewart, 1991; Wise and Leeb, 1993). One method that can be used to affect mesolimbic dopamine activity is through targeting neuronal systems that innervate the dopamine pathway. The endogenous opioid system is one such neuronal system, shown to inhibit or enhance mesolimbic dopaminergic function depending on the type of opioid receptor activated. In particular, it had been proposed that the mu- and the kappa-opioid systems work in concert for the proper maintenance of dopamine release, and specifically that a tonically active mu-system in the ventral tegmental area promotes dopamine release, while a tonically active kappasystem in the nucleus accumbens suppresses dopamine release (Spanagel et al, 1992). Indeed, preexposure to morphine enhances the locomotor response to amphetamine (Vanderschuren et al, 1999; Vezina et al, 1989), while repeated doses of the kappa-agonist U69593 inhibit the locomotor response to subsequent challenges with cocaine (Collins et al, 2001a,b; Shippenberg et al, 2001) or QNP (Acri et al, 2001; Izenwasser et al, 1998).

The purpose of the present investigation was to assess how ongoing dopamine activity induced by the direct dopamine agonist QNP is influenced by coactivation of the kappa-opioid system. We report that cotreatment with U69593 significantly potentiated both acute and sensitized responses to QNP, and more interestingly that it affected only specific components of QNP-induced locomotor behavior, revealing components that appear mediated by pre- and postsynaptic mechanisms.

\section{MATERIALS AND METHODS}

\section{Subjects}

In all, 190 experimentally naive male Long-Evans rats (Charles River, Canada), weighing 250-300 g at the start of the experiment, were used. Rats were housed individually in polyethylene cages $(35 \times 30 \times 16 \mathrm{~cm})$ lined with Tek-Fresh Laboratory bedding made from $100 \%$ reclaimed virgin wood pulp (Harlan Teklad, Madison, WI) in a temperaturecontrolled $\left(22^{\circ} \mathrm{C}\right)$ colony room, maintained on a 12-h lightdark cycle (lights on at 0700), and with free access to food and water. Following arrival, rats were allowed to acclimatize to the colony room for 1 week and were then handled for $2 \mathrm{~min}$ daily for 5 days before the start of the experiment. All treatments were performed during the light phase of the day-night cycle. Animals were housed and tested in compliance with the guidelines described in the Guide to the Care and Use of Experimental Animals (Canadian Council on Animal Care, 1993).

\section{Drugs}

All chemicals and reagents were obtained from Sigma Aldrich. QNP hydrochloride was dissolved in physiological saline and U-69593 ((+)-(5a, 7a, 8 $\beta)-N$-methyl- $N-[7-$ (1-pyrrolidinyl)-1-oxaspirol[4.5] dec-8-yl]-benzeneacetamide in sterile water containing $20 \%$ propylene glycol. All drug doses were administered at a volume of $1.0 \mathrm{ml} / \mathrm{kg}$ and injected subcutaneously under the nape of the neck. When two drugs were coadministered, U69593 was injected first, followed immediately by QNP; for nondrug injections, an equivalent volume of $20 \%$ propylene glycol vehicle and/or saline was administered.

For the chronic QNP treatment, a presynaptic $(0.05 \mathrm{mg} / \mathrm{kg})$ and a postsynaptic $(0.5 \mathrm{mg} / \mathrm{kg})$ dose of QNP were tested. Three lines of evidence indicate that the $0.05 \mathrm{mg} / \mathrm{kg}$ dose is relatively selective for pre- over postsynaptic D2-like receptors. First, electrophysiological studies show that dopamine autoreceptors (Starke, 1981) are 3-10 times more sensitive to dopamine agonists, including QNP, than dopamine receptors located on postsynaptic cells in the striatum or the nucleus accumbens (Kelland et al, 1990; Skirboll et al, 1979; White and Wang, 1986). The typical autoreceptor effects, such as near total inhibition of spontaneous cell firing by midbrain dopamine neurons, can be produced with doses of QNP as low as $0.03 \mathrm{mg} / \mathrm{kg}$ (Mottola et al, 2002; Pitts et al, 1995). Moreover, strong support for the claim that this effect of QNP is produced by stimulation of dopamine autoreceptors is provided by findings that QNP is ineffective in D2 receptor null mice but continues to inhibit dopamine neuron activity in knockout mice lacking the D2Long isoform (Centonze et al, 2002), the isoform characteristic of the postsynaptic dopamine receptor (Khan et al, 1998; Usiello et al, 2000). Second, neurochemical studies show that similarly low doses of dopamine agonists, including QNP, are effective in the inhibition of dopamine release mediated by D2-like presynaptic receptors (Acri et al, 2001; Imperato et al, 1988; Shilliam and Heidbreder, 2003). Finally, behavioral studies show that similarly low doses of dopamine agonists, including QNP, induce locomotor hypoactivity, but doses of QNP greater than $0.1 \mathrm{mg} / \mathrm{kg}$ induce locomotor excitation (Dall'Olio et al, 2002; Eilam et al, 1992; Eilam and Szechtman, 1989; King et al, 1999; Szechtman et al, 1994a; Van Hartesveldt et al, 1992). That the inhibitory effect of low dose QNP on locomotion is produced by stimulation of dopamine autoreceptors is supported by the finding that such doses are inhibitory in the D2Long knockout mice, but not in D2 receptor null mice (Usiello et al, 2000; Wang et al, 2000). With regards to evidence that $0.5 \mathrm{mg} / \mathrm{kg}$ of QNP stimulates postsynaptic dopamine receptors (in addition to autoreceptors), this comes mainly from behavioral studies indicating that, as noted above, QNP doses greater than $0.1 \mathrm{mg} / \mathrm{kg}$ do not induce hypoactivity but, rather, locomotor excitation. Such a postsynaptic mode of action for higher QNP doses is consistent with the observation that the excitatory effect of QNP on locomotion is lost in D2 receptor null mice (Kelly et al, 1998) and is eliminated to another dopamine agonist, apomorphine, in D2Long knockout mice (Usiello et al, 2000). Furthermore, although it is difficult to compare drug doses between in vivo and in vitro studies, it is noteworthy that a similar order of 
magnitude difference exists for QNP concentrations that stimulate the presynaptic D2Short receptor and the D2Long postsynaptic receptor to affect phosphorylation of tyrosine hydroxylase and DARP-32, respectively (Lindgren et al, 2003b).

To induce sensitization, drugs were administered every $3-$ 4 days for a total of 10 injections. This regimen was chosen because the effects of chronic treatment with QNP reach a plateau after 8-10 drug injections administered 2-8 days apart (Szechtman et al, 1994a, b). For U69593, a dose of $0.3 \mathrm{mg} / \mathrm{kg}$ was used as this dose had been shown previously to produce significant changes in QNP-induced locomotor activity (Acri et al, 2001).

For the determination of the dose-response profile to QNP, nine doses were employed $(0,0.01,0.04,0.05,0.06$, $0.07,0.08,0.2$, and $1 \mathrm{mg} / \mathrm{kg}$ ). These doses were selected so as to sample the sensitized dose-response curve described previously (Lomanowska et al, 2004; Szumlinski et al, 1997), taking into account its steep slope in the dose range from 0.04 to $0.08 \mathrm{mg} / \mathrm{kg}$ of QNP.

\section{Apparatus}

The testing environment was a noncolony room containing 10 empty Plexiglas activity chambers $\left(40 \times 40 \times 35 \mathrm{~cm}^{3}\right)$. These were interfaced to a Digiscan 16 monitor and a computer that provided automated recording of locomotor activity using VersaMax software (AccuScan Instruments, Columbus, $\mathrm{OH}$ ). Ventilated Plexiglas lids were used to cover the activity chambers to prevent animals from escaping.

\section{Design}

The ideal study has a between-subjects design with two factors fully crossed: chronic U69593 pretreatment (vehicle vs $0.3 \mathrm{mg} / \mathrm{kg}$ ) and chronic QNP treatment (saline vs $0.05 v s$ $0.5 \mathrm{mg} / \mathrm{kg}$ ), yielding six independent groups. However, because of technical limitations in running all the groups concurrently, the study was conducted as two successive experiments that evaluated separately the effects of a high $(0.5 \mathrm{mg} / \mathrm{kg})$ and a low $(0.05 \mathrm{mg} / \mathrm{kg})$ dose of QNP, as follows.

(1) To examine how sensitization to $0.5 \mathrm{mg} / \mathrm{kg}$ of QNP is affected by the coadministration of U69593, a betweensubjects design with two crossed factors was employed. One independent factor was chronic dose of QNP (0vs $0.5 \mathrm{mg} / \mathrm{kg}$ ) and the other between-subjects factor was chronic dose of U69593 (0 vs $0.3 \mathrm{mg} / \mathrm{kg}$ ). Thus, there were four groups in the study: the experimental group $(N=30)$ was treated chronically with both U69593 $(0.3 \mathrm{mg} / \mathrm{kg})$ and QNP $(0.5 \mathrm{mg} / \mathrm{kg})$, while the three control groups were similarly treated with either vehicle and QNP $(N=30)$, U69593 and saline $(N=21)$, or vehicle and saline $(N=30)$.

(2) To examine how sensitization to $0.05 \mathrm{mg} / \mathrm{kg}$ of QNP is affected by the coadministration of U69593, four groups of rats were tested. The experimental group $(N=20)$ was treated chronically with both U69593 $(0.3 \mathrm{mg} / \mathrm{kg})$ and QNP $(0.05 \mathrm{mg} / \mathrm{kg})$. One control group was similarly treated with vehicle and $0.05 \mathrm{mg} / \mathrm{kg}$ QNP $(N=20)$, and the other control group $(N=19)$ received chronic injections of vehicle and saline. The fourth group received chronic injections of vehicle and $0.5 \mathrm{mg} / \mathrm{kg}$ QNP $(N=20)$ to provide a reference point for an upper level of expected sensitization in this experiment.

There were two parts to each of these experiments. The first part assessed the development of sensitization and the second part evaluated the expression of sensitization. The development of sensitization was tracked by measuring the animal's response to successive injections during the course of 10 treatments. The expression of sensitization was evaluated after the course of 10 injections by determining in each group of rats the dose-response profile to QNP.

A third experiment was also performed in which the effects of U69593 on locomotor activity in rats already sensitized to QNP $(0.5 \mathrm{mg} / \mathrm{kg})$ were evaluated. For this purpose, one of the groups from the second experiment was used as subjects, and in particular the group treated chronically with vehicle plus $0.5 \mathrm{mg} / \mathrm{kg}$ QNP $(N=20)$. These rats received two more injections of $0.5 \mathrm{mg} / \mathrm{kg}$ of QNP after the dose-response test to confirm their sensitized level of responding. Subsequently, for the next four injections, onehalf of the rats continued with their usual vehicle-QNP treatment, while the other half was coadministered U69593 and $0.5 \mathrm{mg} / \mathrm{kg}$ QNP. Behavioral activity was measured after each injection as before; injections were administered at the regular schedule (biweekly) without delay after the end of the second experiment.

\section{Procedure}

On the day of testing, animals were weighed, transported in their home cage to an adjoining noncolony testing room, administered the appropriate injections, placed immediately inside the activity chamber, and their locomotor activity monitored for $90 \mathrm{~min}$ (experiment 1) or $60 \mathrm{~min}$ (experiments 2 and 3). Each animal was tested throughout the study at its assigned time of day and in the same activity chamber. After each use, activity chambers were thoroughly cleaned with Windex diluted with water.

For the dose-response trials assessing the expression of sensitization, rats continued for the next three injections (injections 11-13) with their usual U69593 treatment (ie, vehicle or U69593), but instead of $0.5 \mathrm{mg} / \mathrm{kg}$ of QNP, they now received one of nine doses of QNP $(0,0.01,0.04,0.05$, $0.06,0.07,0.08,0.2$, and $1 \mathrm{mg} / \mathrm{kg}$ ). Each rat received three of these doses, such that in each group the number of subjects per dose was at least 6-7. The assignment to dose was quasirandom in that three restrictions applied: (1) all doses were represented on each of the three trials and the number of subjects/group within a dose on each trial was equivalent across testing; (2) no subject received the highest dose $(1 \mathrm{mg} / \mathrm{kg}$ ) followed immediately by one of the lowest doses $(0,0.01 \mathrm{mg} / \mathrm{kg})$; and (3) the assignment of subjects to dose was equated for performance on the last chronic injection test (injection 10) such that within a group the mean locomotor performance on injection 10 was equivalent across the planned doses.

\section{Data Analysis}

The statistical significance of the effects of kappa cotreatment on sensitization to QNP was evaluated by two main 
methods. One method involved the use of an appropriate analysis of variance (ANOVA) followed by post hoc tests (Duncan multiple range test), while the other method involved the estimation of parameters of a hyperbolic function describing the relationship between locomotor response and number of drug injections or the dose of QNP. The main dependent variable was total distance travelled in the test session and to make the results comparable across tests of different durations (90vs $60 \mathrm{~min}$ ), distance travelled was expressed per unit time $(\mathrm{m} / \mathrm{min})$ and analyzed accordingly. Computations were performed using the SPSS/PC + statistical package. Statistical criteria for significant differences were set at $p<0.05$. Data are plotted as means \pm SEM.

To assess a potential synergistic effect of U69593 on QNPinduced locomotor sensitization, a $2 \times 2$ ANOVA was used where one between-subjects factor was chronic U69593 pretreatment (vehicle $v s 0.3 \mathrm{mg} / \mathrm{kg}$ ) and the other independent factor was chronic QNP treatment $(0.05 v s 0.5 \mathrm{mg} / \mathrm{kg})$. Locomotor activity at injection 10 was analyzed and the groups were constituted from subjects with appropriate treatment in experiments 1 and 2.

A hyperbolic equation was used to describe both the development and the expression of sensitization to QNP. A nonlinear curve-fitting algorithm (Fig.P Version 2.98, Fig.P Software Corporation, Hamilton, ON) was used to estimate the best fit parameters for the following asymmetric sigmoid equation:

$$
R=R_{\min }+\left(R_{\max }-R_{\min }\right) /\left(1+\left(X / X_{50}\right)^{-n}\right)
$$

For development or kinetics of sensitization, $X$ is the number of injections $(I)$ and $R$ is the locomotor response after I number of QNP injections. The estimated parameters are: $R_{\max }$, the maximal response after an infinite number of injections; $X_{50}\left(I_{50}\right)$, the number of injections to reach the half-maximum response; $n$, some power coefficient that represents the sigmoidicity of the function; and $R_{\min }$, which is the lowest response and which was set fixed at the lowest value observed (usually the value at injection 1). In assessment of the expression of sensitization and in particular how sensitization alters the dose-response profile to QNP, $X$ is the dose of QNP $(D)$ and $R$ is the locomotor response at QNP dose $D$. The estimated parameters are: $R_{\max }$, the maximal response at an infinite QNP dose; $X_{50}$ $\left(\mathrm{ED}_{50}\right)$, the QNP dose yielding the half-maximum response; $n$, some power coefficient that represents the sigmoidicity of the function; and $R_{\min }$, which is the lowest response and which was set fixed at the lowest value observed (usually the value at 0.04 or $0.01 \mathrm{mg} / \mathrm{kg}$ of QNP). As the equation has the formalism of Hill equation, $n$ can be considered the Hill coefficient with values of $n$ greater or less than 1, suggesting, respectively, positive or negative cooperativity. For development of sensitization, $I_{50}$ and $R_{\max }$ are taken as measures of the speed of sensitization and the maximum capacity attained, respectively; for expression of sensitization, $\mathrm{ED}_{50}$ and $R_{\max }$ are taken as indices of the drug's potency and efficacy, respectively. The use of this function for sensitization to QNP was described previously (Szechtman et al, 1994b; Szumlinski et al, 1997).

\section{RESULTS}

\section{Effect of U69593 on Development of Sensitization to QNP}

Locomotor response to a postsynaptic dose of QNP $(0.5 \mathrm{mg} / \mathrm{kg})$. As shown in Figure 1a, the coadministration of the kappa agonist U69593 elevated significantly the acute locomotor response to QNP and greatly potentiated the development of locomotor sensitization. A quantitative estimate of this potentiation may be obtained by considering the parameters of the fitted sigmoid function shown in Figure 1a, describing the relationship between the amount of locomotion (distance travelled) and the number of drug injections administered. The values of these parameters are given in Table 1 for rats coadministered U69593 and QNP, and for the control group treated with QNP alone (the function did not fit the data of the two remaining groups). Two parameters are of particular relevance: $I_{50}$ (the number of injection to reach the half-maximum response) as an index of the rate of sensitization, and $R_{\max }$ (the maximum level of locomotor responding achievable) as an index of the magnitude of sensitization reached. Kappa coadministration had a significant effect on both of these parameters. Accordingly, it accelerated the speed with which sensitization developed as evidenced by a drop in $I_{50}$ from 6.3 to 3.9 injections; moreover, it raised the magnitude of locomotor sensitization almost two-fold as evidenced by the increase in $R_{\max }$ from 5.2 to $9.7 \mathrm{~m} / \mathrm{min}$ (Table 1). Interestingly, in contrast to its potentiating effects on speed of sensitization $\left(I_{50}\right)$ and capacity of sensitized responding $\left(R_{\max }\right)$, kappa cotreatment reduced from 4.7 to 1.7 the parameter that describes the function sigmoidicity $(n)$. A number of interpretations for $n$ are plausible (Szechtman et al, 1994b), including the possibility that allosteric modulation in sensitization to QNP involves a site that is sensitive to U69659.

As shown in Figure 2a, coadministration of the kappa agonist had also marked effects on the time course of the locomotor response to $\mathrm{QNP}$ - both on the acute profile as well as on the dynamics of change across repeated injections. These effects can be described within a framework identified previously (Eilam and Szechtman, 1989; Szechtman et al, 1994a,b) for the time course of the locomotor response to acute and chronic QNP, a framework also evident in the present study for the QNP alone rats (Figure 2, VQhigh group). Typically, the locomotor response to acute QNP has three phases: a period of initial inhibition lasting about $5 \mathrm{~min}$, a second phase of relative inhibition for an additional $15-30 \mathrm{~min}$, followed finally by a period of locomotor excitation, compared to saline controls. With subsequent injections of QNP $(0.25-0.5 \mathrm{mg} / \mathrm{kg})$, the initial inhibitory phase remains unperturbed, while the duration of relative inhibition shortens and ultimately disappears. Concurrently, the peak of excitation increases with repeated injections and the onset of excitation advances progressively until ultimately excitation is evident within 5-10 $\mathrm{min}$ of drug injection (Lomanowska et al, 2004; Szechtman et al, 1994a,b). In the present study, a similar pattern of locomotor responding to QNP alone was evident (Figure 2a). Interestingly, the repeated coadministration of the kappa agonist U69593 had an effect on the latter two 
Effects of $U 69593$ on Locomotor Sensitization to QNP

a

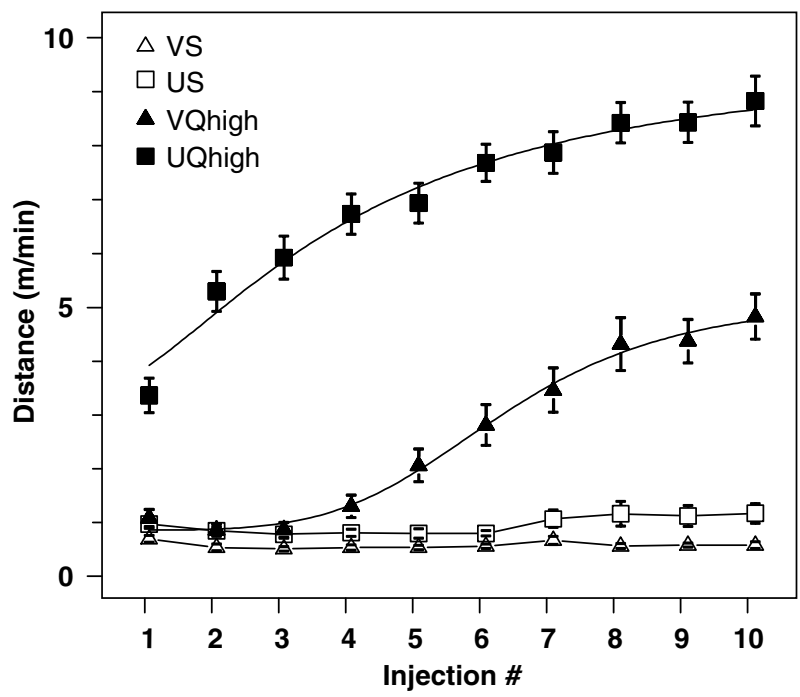

b

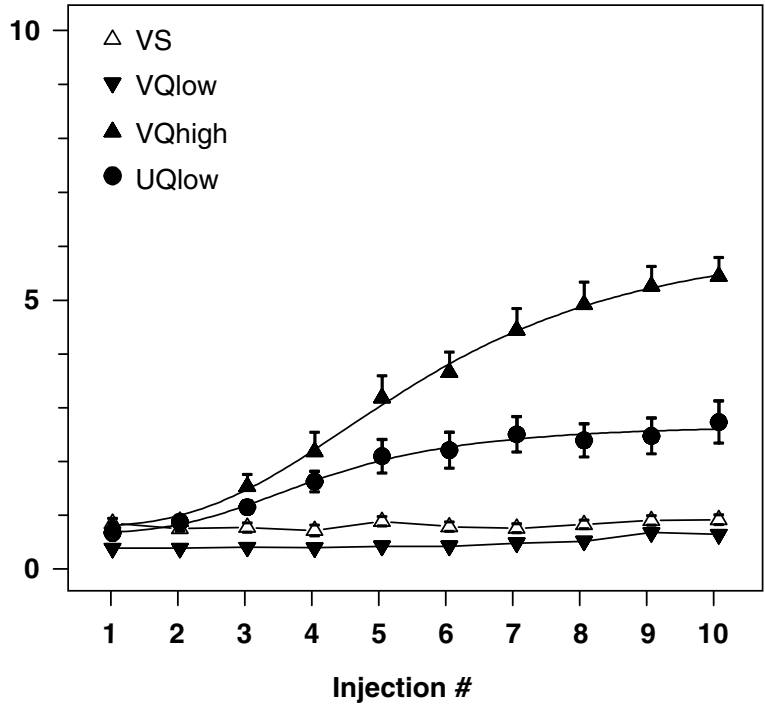

Figure I Effect of $U 69593(0.3 \mathrm{mg} / \mathrm{kg})$ on the development of locomotor sensitization to (a) postsynaptic $(0.5 \mathrm{mg} / \mathrm{kg})$ and (b) presynaptic $(0.05 \mathrm{mg} / \mathrm{kg})$ doses of QNP. Locomotor activity is measured as total distance travelled during the test session and is normalized to the duration of the test session in units of meters per minute $(\mathrm{m} / \mathrm{min})$. Symbols indicate mean \pm SEM; for some data points, SEM is smaller than the size of the symbol. Smooth thick lines show the best fit estimate of the asymmetric sigmoid equation indicated in the Materials and methods section, with parameters given in Table I; thin straight lines connecting group symbols indicate that the function did not fit those data, consistent with no evidence of locomotor sensitization. Injections were administered 3-4 days apart. In the left graph (a), the significant differences at each injection are: for UQhigh, all points compared to any other group; for VQhigh, injection 5 compared to VS and injections 6-10 compared to any other group at the corresponding injection. In the right graph (b), the significant differences are: for VQhigh, injections 4-10 compared to any other group; for UQlow, injections 4-10 compared to any other group; for VQlow, injections 2, 3, 5-8 compared to any other group; $p<0.05$ (Duncan multiple range test). Legend: VS = vehicle plus saline, US $=$ U69593 plus saline, VQhigh $=$ vehicle plus $0.5 \mathrm{mg} / \mathrm{kg}$ QNP, UQhigh =U69593 plus $0.5 \mathrm{mg} / \mathrm{kg}$ QNP, VQlow = vehicle plus $0.05 \mathrm{mg} / \mathrm{kg}$ QNP, UQlow= U69593 plus $0.05 \mathrm{mg} / \mathrm{kg}$ QNP.

Table I Estimate and SE of Parameters for the Curves in Figures I and 5

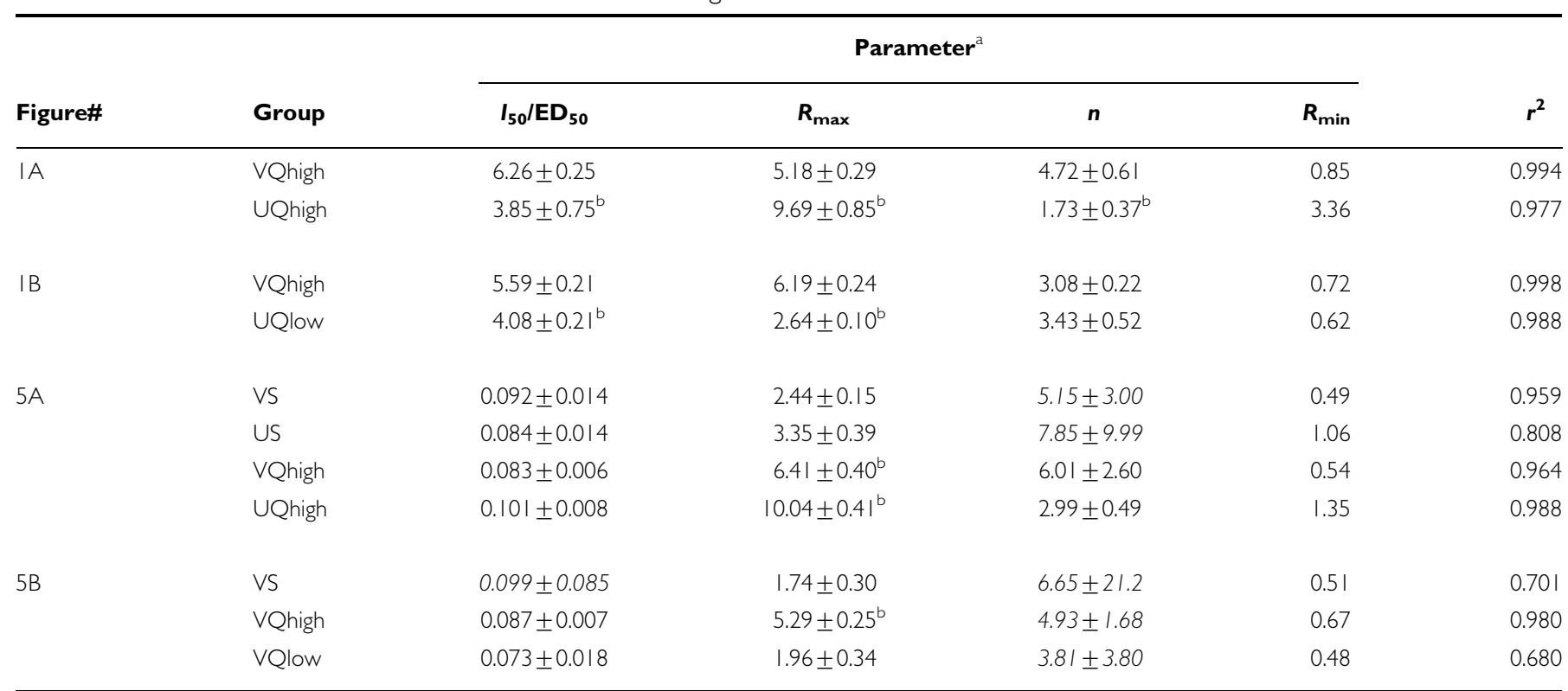

aEquation (see Materials and methods) fitted to the data of the indicated groups and shown in Figures I and 5. $I_{50}$ is the number of drug injections required to reach the half-maximal response and $\mathrm{ED}_{50}$ is the dose in $\mathrm{mg} / \mathrm{kg}$ with the half-maximal response ( $I_{50}$ is above and $\mathrm{ED}_{50}$ is below the double horizontal line), $R_{\mathrm{max}}$ is the maximal response (in meters travelled per minute), $n$ is a parameter describing the sigmoidicity of the curve, $R_{\min }$ is the lowest response that served as a fixed parameter in the equation, and $r^{2}$ indicates the square of the correlation coefficient between raw and fitted data. Standard error (SE) refers to the standard error of the estimate of the parameter; the estimate of each parameter is statistically significant, except for the values indicated in italic font. For groups absent from the table, a significant fit of the function to the data did not exist. Group abbreviations correspond to those in the figures: VS = vehicle plus saline, US $=$ U69593 plus saline, VQhigh $=$ vehicle plus $0.5 \mathrm{mg} / \mathrm{kg}$ quinpirole, UQhigh =U69593 plus $0.5 \mathrm{mg} / \mathrm{kg}$ quinpirole, VQlow = vehicle plus $0.05 \mathrm{mg} / \mathrm{kg}$ quinpirole, UQlow= U69593 plus $0.05 \mathrm{mg} / \mathrm{kg}$ quinpirole. ${ }^{b} p<0.05$ compared to any other group in the set demarcated by horizontal lines, $t$-test. 
Effects of U69593 on Time Course of Locomotor Response to QNP

a

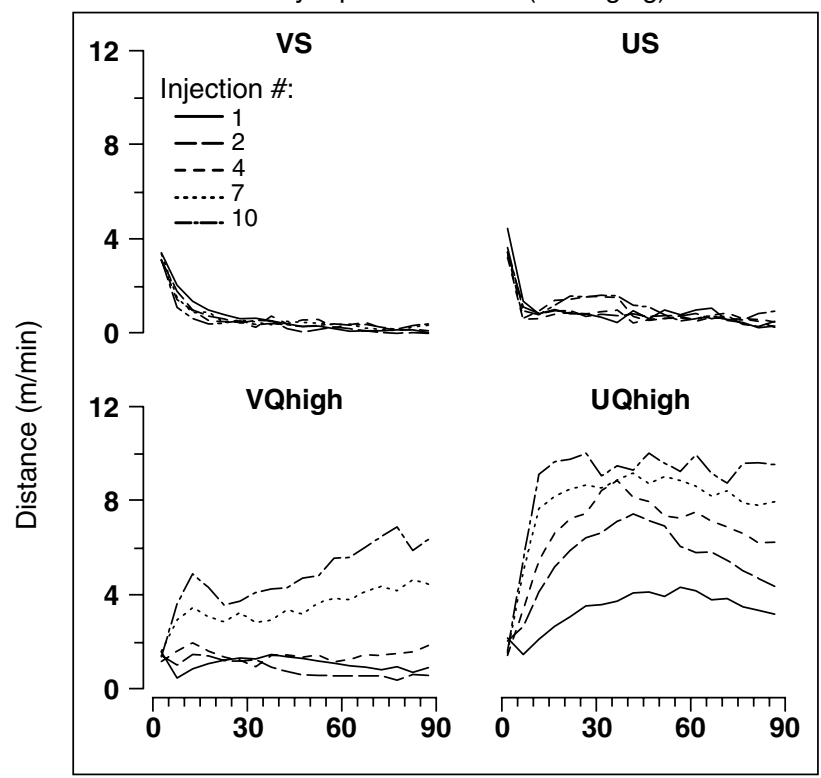

Time After Injection (min)

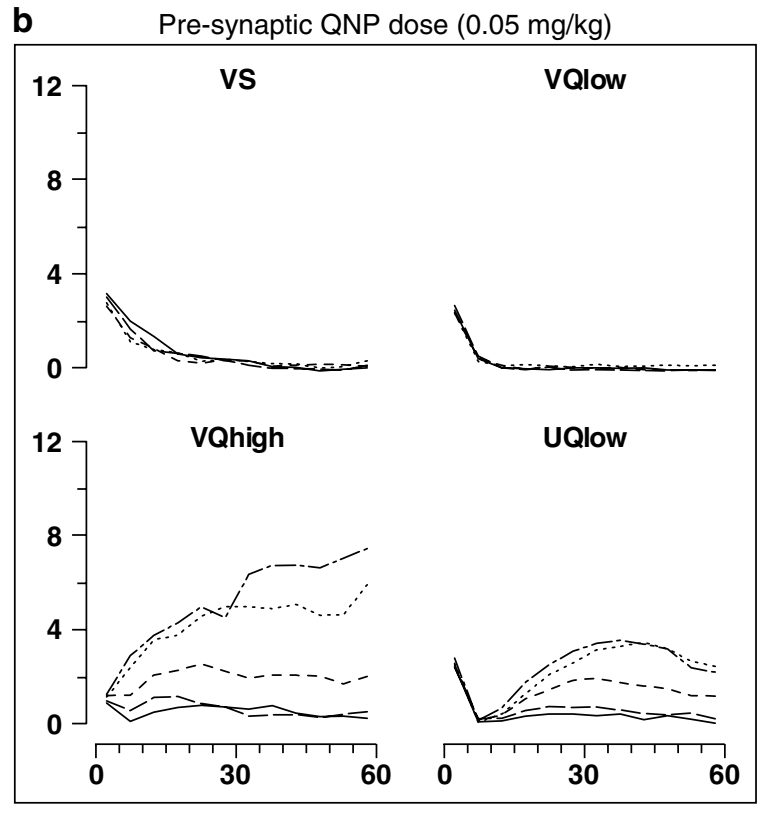

Time After Injection ( $\mathrm{min})$

Figure 2 Time course of locomotor responses to cotreatment with $U 69593$ and (a) postsynaptic $(0.5 \mathrm{mg} / \mathrm{kg})$ or (b) presynaptic (0.05 mg/kg) doses of QNP during the course of repeated injections of the drugs. Distance travelled in 5-min intervals is shown and is plotted at the interval midpoint in units of meters per minute $(\mathrm{m} / \mathrm{min})$. For clarity, only selected injections are shown. Legend: VS $=$ vehicle plus saline, US $=U 69593$ plus saline, VQhigh $=$ vehicle plus $0.5 \mathrm{mg} / \mathrm{kg}$ QNP, UQhigh=U69593 plus $0.5 \mathrm{mg} / \mathrm{kg}$ QNP, VQlow = vehicle plus $0.05 \mathrm{mg} / \mathrm{kg}$ QNP, UQlow $=$ U69593 plus $0.05 \mathrm{mg} / \mathrm{kg}$ QNP.

phases (relative inhibition and excitatory phases) but little influence on the first one, the initial inhibition. We examine first the contrasting effects on the two inhibitory phases and then the kappa cotreatment effect on the excitatory phase.

The evidence that chronic U69593 cotreatment had little impact on QNP-induced locomotor depression in the first 5 min (initial inhibition) is presented in Figure 3a (left panel) and supported by the following statistical analyses. First, in the kappa agonist cotreated group, as in every other group, there did not exist a significant linear trend across injections that would suggest a systematic change during the course of chronic treatment (the dashed lines depict overall group means). Second, between-group comparisons at end of treatment (injection 10) showed no difference between the kappa agonist cotreated and the QNP-alone groups, strengthening the notion that repeated injections of U69593 did not modify the initial inhibitory period. Finally, although a between-groups comparison at the start of treatment (injection 1) showed significantly less locomotor inhibition in the U69593 cotreated group than in the QNPalone rats (Figure 3a, left panel), this attenuation tolerated rather quickly-after three injections inspection of the graph suggests. Thus, while the initial inhibition induced by QNP was attenuated by U69596 at the start of chronic cotreatment, the repeated coadministration of the kappa agonist had no long-lasting effects on the initial depressive effects induced by QNP.

The evidence for a marked effect of chronic U69593 cotreatment on the relative inhibitory period (indexed by the amount of locomotion from 5 to $20 \mathrm{~min}$ after drug injection) is shown in Figure 3a (right panel). As can be seen, the regression line for locomotion across injections was significantly steeper in the kappa cotreated than in the QNP-alone group (slopes for U69595 cotreated and QNP-alone groups: $0.63 \pm 0.05$ vs $0.38 \pm 0.02 \mathrm{~m} /$ injection; $p=0.001$ ), suggesting that the depressive effects induced by QNP (which normally disappear with chronic injections of QNP) are eliminated faster with kappa agonist cotreatment. Moreover, the intercept in the kappa cotreated rats was significantly higher than in the QNP-alone group $(2.25 \pm 0.30$ vs $0.38 \pm 0.14 \mathrm{~m} ; p<0.05)$, further suggesting that the effect of kappa agonist cotreatment on the relative inhibitory period is present even upon an acute injection of QNP.

Finally, inspection of Figure 2a shows that U69593 cotreatment had a marked effect on at least two parameters that characterize the excitatory phase induced by QNP, magnitude, and time to peak response. In terms of peak amplitude, kappa cotreatment potentiated the maximal response attained such that in U69593 cotreated rats the peak response on injection 2 was already equivalent to the peak response on Injection 10 in the QNP-alone group (7.4 $\pm 0.5 v s 6.9 \pm 0.7 \mathrm{~m} / \mathrm{min}$, respectively). Similarly, chronic U69593 cotreatment advanced the time to peak amplitude such that by Injection 10 the maximal response was achieved within approximately $15 \mathrm{~min}$ (and maintained thereafter), in contrast to the 60-90 min latency for QNP alone.

Thus, the coadministration of the kappa agonist potentiated the development of sensitization by affecting several characteristics of the locomotor response to QNP: U69593 reduced the duration of the relative inhibitory phase; increased the magnitude of the peak locomotor response; advanced the onset of the maximal response to within 


\section{Effects of U69593 on QNP-Induced Inhibition}
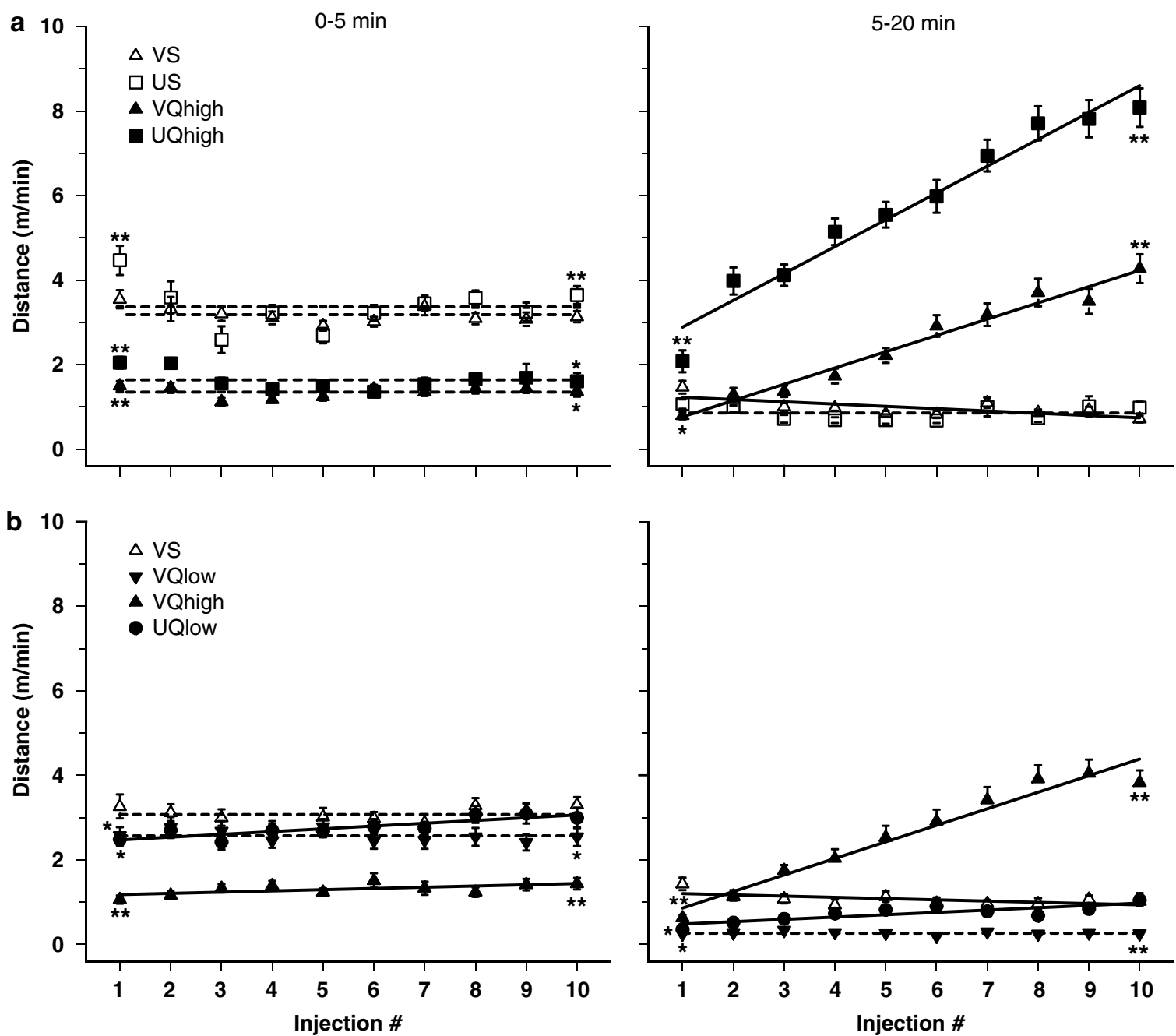

Figure 3 Effect of U69593 cotreatment with (a) postsynaptic $(0.5 \mathrm{mg} / \mathrm{kg})$ and (b) presynaptic $(0.05 \mathrm{mg} / \mathrm{kg})$ doses of QNP on two inhibitory phases induced by QNP during the course of 10 injections. Left and right panels in each figure represents the QNP-induced locomotor depression as seen, respectively, during the initial inhibitory phase from 0 to $5 \mathrm{~min}$ and the relative inhibitory phase from 5 to 20 min after drug injection. Each point represents the total distance travelled ( + SEM) in the indicated interval, normalized to interval duration and expressed in units of meters per minute ( $\mathrm{m} /$ min). Solid lines represent significant regression fits. Dashed lines represent the overall group mean and indicate that the regression fit was nonsignificant. Comparisons between groups were performed only at injections I and 10 (Duncan multiple range test). ${ }^{*} * x<0.05$ vs any other group; $* p<0.05$ vs saline controls

minutes of drug injection; and, finally, prolonged the duration of the maximal response for the length of the testing period.

Locomotor response to a presynaptic dose of QNP $(0.05 \mathrm{mg} / \mathrm{kg})$. Not only did the coadministration of the kappa agonist U69593 potentiate sensitization to a postsynaptic dose of QNP, it also influenced the response to a presynaptic dose, a dose of QNP that normally results in locomotor inhibition rather than sensitization (Lomanowska et al, 2004). As shown in Figure 1b, the presynaptic dose produced the expected locomotor inhibition, acutely and virtually throughout the course of drug treatment. However, the coadministration of U69593 eliminated this inhibitory response, acutely and throughout chronic treatment (Figure 1b). Surprisingly, with chronic treatment, the coadministration of U69593 induced locomotor sensitization to the presynaptic dose of QNP. This sensitization in the cotreated rats was evident from their significantly higher locomotor response at the end of chronic treatment (injection 10) compared to their acute response $(2.7 \pm 0.4$ at injection $10 v s 0.6 \pm 0.1 \mathrm{~m} / \mathrm{min}$ at injection $1, p<0.05$, paired $t$-test), as well as from their significantly greater locomotion at injection 10 compared to either saline $(0.9 \pm 0.1 \mathrm{~m} / \mathrm{min})$ or low-dose QNP $(0.6 \pm 0.1 \mathrm{~m} / \mathrm{min})$ controls $(p<0.05$, for each comparison).

However, the magnitude of this sensitization, as evidenced by the maximal response $R_{\max }$ (Table 1), was less than one-third of the sensitization achieved by cotreatment of the kappa agonist with a postsynaptic dose of QNP. Nevertheless, coadministration of the kappa agonist with the presynaptic dose of QNP did increase the rate of sensitization, as evidenced by fewer injections required to reach the half-maximal response $(4.1+0.2$ injections for the cotreated rats $v s 5.6+0.2$ injections for the $0.5 \mathrm{mg} / \mathrm{kg}$ QNP-alone rats; Table 1). 
Figure $2 \mathrm{~b}$ shows the dynamics of the locomotor response to drug treatments across the course of 10 injections. As seen from an inspection of the figure, coadministration of the kappa agonist with low-dose QNP had a limited effect on the excitatory phase induced by QNP in that only one parameter (peak amplitude) increased across injections, without affecting the latency to peak amplitude or duration of maximal response (compare Figure 2a). Yet, for QNPinduced locomotor inhibition, kappa cotreatment had a broad impact, attenuating the depressive effects of QNP during the initial inhibitory period (first $5 \mathrm{~min}$ after drug injection), as well as during the subsequent relative inhibitory phase (5-20 min after drug injection). This attenuation is shown in Figure $3 b$ by the presence of positive regression lines for the kappa plus low-dose QNP group (UQlow group), indicating diminishment across injections of the depressive effects of QNP on locomotion. Similarly, attenuation is shown by the presence of a significant difference between the kappa cotreated rats and saline controls at injection 1 , but the absence of this significant difference at injection 10 (Figure $3 \mathrm{~b}$ ).

Synergistic effect of U69593 and QNP on locomotor sensitization. As shown in Figure 4, at the end of treatment to induce sensitization (injection 10), the interaction effect between U69593 dose and QNP dose was statistically significant $(\mathrm{F}(1,116)=4.48, p<0.05)$. Inspection of the figure suggests that this interaction effect reflects a relatively greater effect on locomotor sensitization pro-

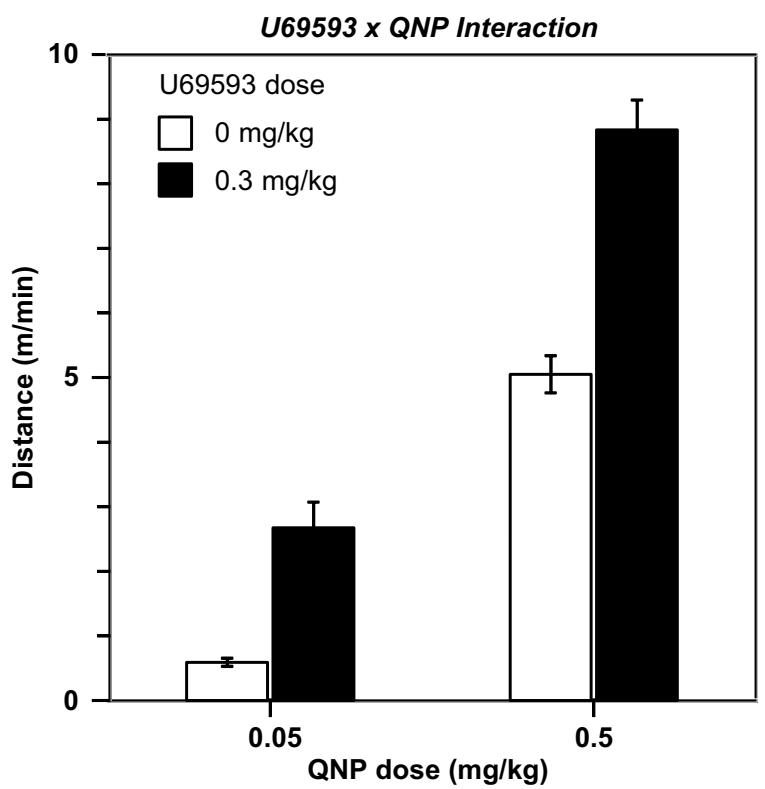

Figure 4 A synergistic effect between $U 69593$ and QNP on locomotor sensitization. Locomotor activity was measured as distance travelled during the entire test session at injection 10 (the last injection during the stage for induction of sensitization) and is expressed as mean distance (+ SEM) in meters per minute. The data from groups injected with 0.5 and $0.05 \mathrm{mg} / \mathrm{kg}$ of QNP were analyzed using a QNP dose $(0.05,0.5 \mathrm{mg} / \mathrm{kg}) \times \cup 69593$ dose $(0,0.3 \mathrm{mg} / \mathrm{kg})$ ANOVA. The interaction effect, depicted in the figure, was significant $(F(I,|| 6)=4.48, p<0.05)$, suggesting a potentiation by U69693 of the response to the higher dose of QNP. The main effects were also significant (for QNP dose, $F(I, \mid$ I 6) $=190.619$, $p<0.001$; for U69593 dose, $F(I,|| 6)=58.334, p<0.00 I)$. duced by the coadministration of the kappa agonist with the postsynaptic dose of QNP than the coadministration of the kappa agonist with the presynaptic dose of QNP.

\section{Effect of U69593 on Expression of Sensitization to QNP}

QNP dose-response profile in rats sensitized with $0.5 \mathrm{mg} / \mathrm{kg}$ of QNP. As shown in Figure 5a, in rats sensitized to QNP (right panel), U69593 shifted upwards along the $Y$-axis the QNP dose-response curve, blocking the depressive effects of very low doses of QNP $(0.01 \mathrm{mg} / \mathrm{kg})$, but elevating the excitatory effects produced by higher doses of QNP. This profile is supported by the following statistical analysis. In rats sensitized with $0.5 \mathrm{mg} / \mathrm{kg}$ of QNP, depression of the locomotor response to low-dose QNP $(0.01 \mathrm{mg} / \mathrm{kg})$ is evident by significantly less locomotion compared to an injection of saline $(0.8 \pm 0.05$ vs $0.5 \pm 0.06 \mathrm{~m} / \mathrm{min}$ for saline and $0.01 \mathrm{mg} / \mathrm{kg}$, respectively; $p<0.05, t$-test) and the blockade of this depressive effect is suggested by the absence of a similar difference in the kappa cotreated rats $(0.9 \pm 0.08$ vs $1.3 \pm 0.2 \mathrm{~m} / \mathrm{min}$ for saline and $0.01 \mathrm{mg} / \mathrm{kg}$, respectively; NS). Support for potentiation of the excitatory effects induced by higher doses of QNP is provided in Table 1, which shows a significantly higher maximal response $\left(R_{\max }\right)$ in kappa cotreated than in QNP-alone rats, and no group difference in QNP potency $\left(\mathrm{ED}_{50}\right)$.

The effect of U69593 in nonsensitized rats on the QNP dose-response curve (Figure 5a, left panel) is more difficult to characterize. Specifically, while inspection of the graph would suggest attenuation by the kappa agonist of the depressive effects induced by low-dose QNP, such an inference is questionable because of insufficient power to detect in the chronic saline-alone group a statistically reliable depressive effect of QNP. However, the apparent absence of a kappa agonist effect on the excitatory response to higher doses of acute QNP is probably real, because neither the maximal response $\left(R_{\max }\right)$ nor QNP potency $\left(E D_{50}\right)$ was different in the chronic kappa-alone group compared to the chronic saline-alone animals (Table 1).

Dose response to QNP in rats sensitized with $0.05 \mathrm{mg} / \mathrm{kg}$ of QNP. The shape of the QNP dose-response curve in rats cotreated with U69593 and $0.05 \mathrm{mg} / \mathrm{kg}$ of QNP was unusual in that it was remarkably flat (Figure 5b, middle panel). Kappa agonist cotreatment eliminated the depressive effects of lower doses of QNP, but, surprisingly, it had no effect in potentiating the excitatory effects induced by higher doses of QNP, a result that yielded a relatively uniform level of locomotion across QNP doses. Such a pattern was unique to cotreatment with the presynaptic dose of QNP, as in the other three groups the QNP dose-response curve followed the expected profile (Figure $5 \mathrm{~b}$ ).

It may be noteworthy that in seven of the eight doseresponse curves obtained in the present study (Figure 5a and $\mathrm{b}$ ), the locomotor response to $1 \mathrm{mg} / \mathrm{kg}$ was lower than the response to $0.2 \mathrm{mg} / \mathrm{kg}$ of QNP. The one exception was in the group of rats sensitized by cotreatment of U69593 with $0.5 \mathrm{mg} / \mathrm{kg}$ of QNP (Figure $5 \mathrm{a}$, right panel). A similar difference between the response to 1 and $0.2 \mathrm{mg} / \mathrm{kg}$ of QNP had been observed in other studies (Szumlinski et al, 1997, 2000) but not always (Lomanowska et al, 2004). We do not have an explanation for this drop in the dose-response 
a

Effects of U69593 on Expression of Locomotor Sensitization to QNP
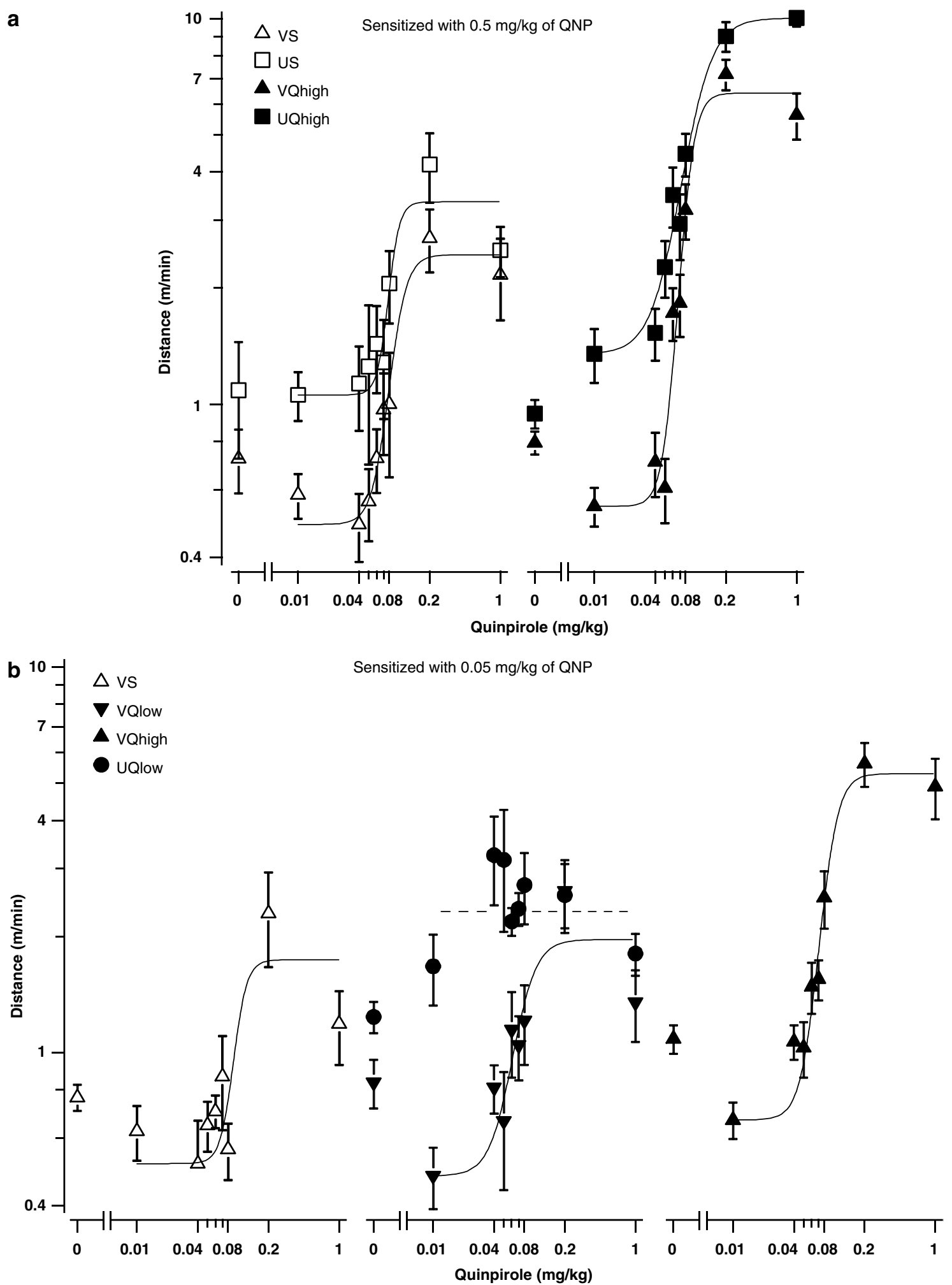

Figure 5 Effect of $U 69593$ cotreatment on the QNP dose-response profile in rats sensitized with either (a) a postsynaptic (0.5 mg/ $/ \mathrm{kg}$ ) or (b) a presynaptic $(0.05 \mathrm{mg} / \mathrm{kg})$ dose of QNP. Locomotor activity was measured as distance travelled in $90 \mathrm{~min}$ (a) or 60 min (b) and is expressed as mean distance $(+\mathrm{SEM})$ in meters per minute. For each dose, $N=6-9$; every rat received in random order three of the nine test doses. Lines show the best fit estimate of the equation indicated in the Materials and methods section, with parameters given in Table I. For the UQlow group, the line represents the overall group mean because the equation could not be fitted to these data, consistent with the lack of a main effect of dose $(F(I, 5 I)=\mid .6 I, p=0.15)$. Legend: VS = vehicle plus saline, US =U69593 plus saline, VQhigh = vehicle plus $0.5 \mathrm{mg} / \mathrm{kg}$ QNP, UQhigh $=$ U69593 plus $0.5 \mathrm{mg} / \mathrm{kg}$ QNP, VQlow $=$ vehicle plus $0.05 \mathrm{mg} / \mathrm{kg}$ QNP, UQlow $=$ U69593 plus $0.05 \mathrm{mg} / \mathrm{kg}$ QNP. 
curve, as mouthing is not necessarily a feature of the higher dose of QNP.

Effect of U69593 on expression of sensitization in rats presensitized with $0.5 \mathrm{mg} / \mathrm{kg}$ of QNP. Figure 6 shows the locomotor response of rats to their final injection of chronic QNP treatment (injection 15); half of the rats continued to receive the same dose of QNP for the next four injections (VQhigh subgroup), while the other half continued to receive cotreatment of U69593 and QNP (QhighU subgroup). On injection 15 the locomotor response of the two halves were equivalent $(p>0.05 ; t$-test $)$. However, on injection 19, U69593 cotreatment resulted in a significant increase in the locomotor response to QNP compared to those rats receiving QNP alone ( $p=0.03$; $t$-test), suggesting that U69593 cotreatment augmented the expression of QNPinduced locomotor sensitization. A regression analysis across injections revealed that in the rats which continued to be treated with QNP alone there was a small but significant change in locomotion across the five injections ( slope $=0.28 \pm 0.06 \mathrm{~m} /$ injection, $p<0.05$ ). In contrast, a marked and significant positive slope was present in the rats cotreated with U69593 and QNP (slope $=0.91+0.16 \mathrm{~m}$ / injection, $p<0.05)$. More importantly, the asymmetric sigmoid function provided an excellent fit $\left(r^{2}=0.99\right)$ to these data, yielding an $R_{\max }$ value of $8.3+0.3 \mathrm{~m} / \mathrm{min}$, a value that was within the range obtained in the rats sensitized

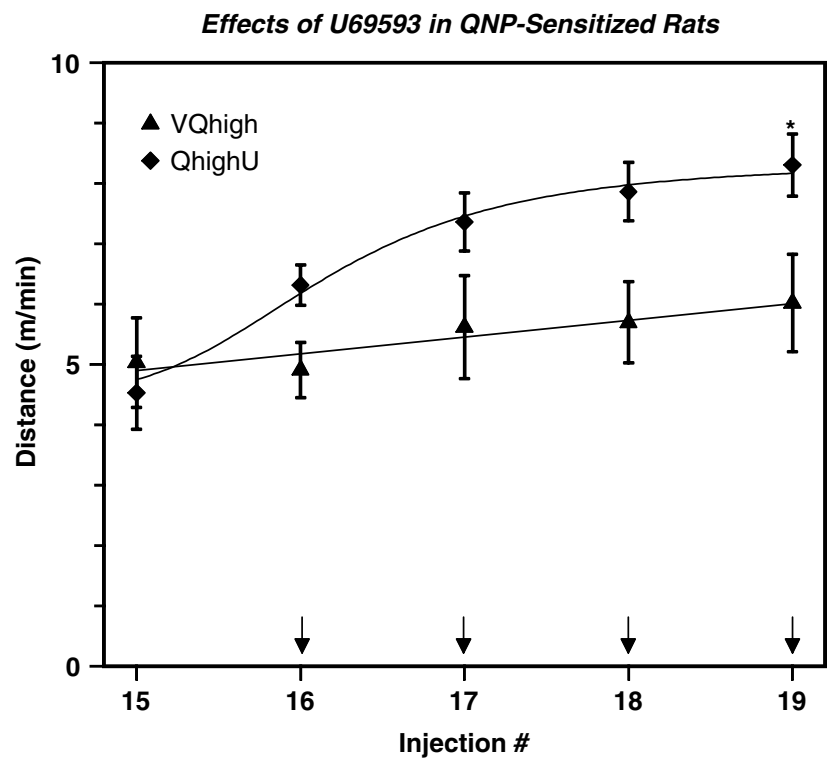

Figure 6 Effects of $\mathrm{U} 69593$ on the expression of sensitized locomotion to QNP. Locomotor activity was measured as distance travelled in $60 \mathrm{~min}$ and is expressed as mean distance $(+$ SEM) in meters per minute. The thin solid line represents a significant regression fit $(y=0.028 \pm 0.06 x+$ $4.61 \pm 0.21$ ). The thick solid line shows the best fit estimate of the equation indicated in the Materials and methods section, and yielded the following parameter estimates $\left(I_{50}=2.2+0.2 ; \quad R_{\max }=8.3+0.3 \mathrm{~m} / \mathrm{min}\right.$ $\mathrm{N}=3.6+1 . \mathrm{I}$; Min was fixed at $4.53 \mathrm{~m} / \mathrm{min}) . I_{50}$ refers to the number of injections required to reach the half-maximum response, where the first injection is taken as injection 15. Arrows indicate trials with U69593 cotreatment for the QhighU group. Groups were compared by $t$-test at injection 15 (NS) and injection $19(p=0.03$, indicated by *). Legend: VQhigh = vehicle plus $0.5 \mathrm{mg} / \mathrm{kg}$ QNP, Qhigh U $=U 69593$ plus $0.5 \mathrm{mg} / \mathrm{kg}$ QNP. with the cotreatment of U69593 and $0.5 \mathrm{mg} / \mathrm{kg}$ of QNP from injection 1 onwards $(9.7+0.9 \mathrm{~m} / \mathrm{min}$; see Table 1$)$. The latter observation suggests that kappa agonist cotreatment need not be present during the development of sensitization, but can equally potentiate the locomotor response to QNP in rats that are already fully sensitized.

\section{DISCUSSION}

The present study found that chronic cotreatment with U69593 markedly potentiated the development of sensitization to a postsynaptic dose of QNP, nearly doubling the speed of sensitization and the level achieved. Moreover, chronic U69593 cotreatment with a presynaptic dose of QNP switched the effects of QNP from locomotor depression to locomotor excitation, and, ultimately, locomotor sensitization. Finally, U69593 cotreatment with a presynaptic dose of QNP changed a different set of measures of sensitization than did cotreatment with a postsynaptic dose of the dopamine agonist. Taken together, these findings suggest that sensitization is not a unitary phenomenon, but has components that are relatively independent, mediated by distinct pre- and postsynaptic mechanisms and modulated by kappa receptor activity. Below, we discuss the evidence for the presence of distinct components of sensitization to QNP, suggest mechanisms embodied in a model of sensitization, and finally propose that the effects of kappa receptor stimulation are dependent on the context surrounding dopamine system activation.

\section{Components of Sensitization}

The primary type of evidence for relatively independent components yielding behavioral sensitization to QNP comes from findings showing that different treatments produced an uncoupling among measures of sensitization, altering some but leaving other aspects of sensitized responding unchanged. Such results were observed for measures of the rate and the magnitude of sensitization, for time-course parameters of QNP-induced locomotor excitation across injections, and for the depressive $v s$ excitatory effects of QNP. We discuss these measures in turn.

The inference of relative independence between rate and magnitude of sensitization is educed by observations that U69593 cotreatment invariably accelerated the rate of sensitization but its effects on the magnitude of sensitization were dependent on the dose of coadministered QNP. Specifically, kappa agonist cotreatment with a postsynaptic dose of QNP hastened the speed of sensitization (as indexed by the number of injections to reach the half-maximal response, $I_{50}$ ) from about six to four injections (see Table 1), and elevated the magnitude of sensitization $\left(R_{\max }\right)$ to almost double the level attained by rats treated with QNP alone. However, the same accelerated speed of sensitization of about four injections was also produced when the kappa agonist was coadministered with a presynaptic dose of QNP, but the level of sensitization attained then was only one-third of the level reached by rats treated with QNP alone, revealing an uncoupling between effects on rate and magnitude of sensitization. A similar dependence on dose of coadministered QNP was found in the analysis of the level of sensitization reached at the last (tenth) injection of 
chronic treatment: As shown in Figure 4, the effects of U69593 synergized with QNP dose, suggesting an interaction between the effects of QNP and the kappa agonist, an interaction that was absent for the measure of speed of sensitization $\left(I_{50}\right.$, Table 1$)$. Thus, kappa agonist cotreatment seems to have a determining effect on the mechanism that engenders the development of sensitization, but only a modulatory influence on the mechanism that controls the point at which such growth will stop, as indexed by the level of sensitization attained.

A similar dissociation in measures of sensitized responding was observed for parameters describing the time-course of QNP-induced locomotor excitation across injections. Normally, during the course of repeated injections with QNP, the time-response profile for locomotor excitation after drug injection shows three progressive changes: the maximum or the peak of the locomotor response rises progressively with each subsequent drug injection; the maximum response arrives progressively sooner after injection; and finally, the maximal response persists for a progressively longer period of time during the test session (Szechtman et al, 1994a, b present study). Kappa agonist cotreatment with a postsynaptic dose of QNP potentiated these three parameters dramatically (Figure 2a). However, chronic U69593 cotreatment with a presynaptic dose of QNP produced only a progressive increase in the peak response, without advancing the time of the maximal response or extending its duration, thus suggesting that changes in the peak response are a component of the process of sensitization that occurs relatively independently from any accompanying changes in the latency or duration of the maximal response.

A final set of observations indicates that across injections the progressive reduction in depressive and increase in excitatory effects of QNP (Lomanowska et al, 2004; Szechtman et al, 1994a,b), are likewise probably relatively independent processes. Again, such an inference follows from the uncoupling of changes produced by kappa agonist coadministration. Normally, there are two phases to the depressive effects of QNP during the course of drug action: an initial inhibitory period that lasts about $5 \mathrm{~min}$ and a subsequent relative inhibitory phase that lasts from 5 to 20 min after drug injection, with only the relative inhibitory phase gradually diminishing across injections and ultimately becoming supplanted by locomotor excitation (Eilam and Szechtman, 1989; Szechtman et al, 1994a,b; present study). However, chronic cotreatment of U69593 with the presynaptic dose of QNP resulted in tolerance of the initial inhibition, an effect that was not observed during cotreatment of U69593 with a postsynaptic dose of QNP. Kappa agonist cotreatment had also a dose-dependent dissociation effect on the relative inhibitory period. Specifically, kappa agonist coadministration with the postsynaptic dose of QNP accelerated tolerance of the relative inhibitory period and its replacement by locomotor excitation. In contrast, U69593 cotreatment with the presynaptic dose of QNP yielded only tolerance of the relative inhibitory period that was not supplanted by locomotor excitation. Thus, tolerance of the initial or relative inhibitory phases may occur relatively independently of each other; furthermore, tolerance of locomotor inhibition does not necessarily yield locomotor excitation.
Perhaps the clearest demonstration of the relative independence between tolerance of locomotor inhibition to QNP and sensitization of locomotor excitation is provided by the dose-response evaluation of the expression of QNP sensitization (Figure 5). Even though chronic U69593 and QNP cotreatment eliminated in sensitized rats the depressive effects of very low doses of QNP, this did not necessarily induce sensitized responding to higher doses of QNP: It did so if rats were sensitized with chronic coadministration of the postsynaptic dose of the drug, but not if they received chronic coinjections of the presynaptic QNP dose. Considering that the magnitude of sensitization in the latter case was very minimal, conceivably, mere tolerance of QNP-induced locomotor inhibition can result in only a partial, but not in a full-blown, sensitization.

\section{A Model of QNP Sensitization}

The distinct behavioral components of QNP sensitization identified here may reflect changes in separate neurochemical mechanisms. We outline first how the behavioral components may operate together to produce locomotor sensitization and then consider some possible underlying mechanisms.

As across dose and across time the acute effects of dopamine agonists on behavior are generally biphasicbehavioral inhibition followed by behavioral excitation (Harkin et al, 2000; Kelsey and Carlezon Jr, 2002; Van Hartesveldt et al, 1992, 1994) — it has been hypothesized that sensitization is the mere outcome of tolerance of the drug depressive effects (Baker and Tiffany, 1985; Hinson and Siegel, 1983). However, the present finding that chronic kappa agonist cotreatment with low-dose QNP $(0.05 \mathrm{mg} / \mathrm{kg})$ yielded tolerance to the depressive effects of QNP without full-blown sensitization (as evidenced by lack of a sensitized response to higher doses of QNP; Figure 5) falsifies this hypothesis.

Rather than mere tolerance of drug-depressive effects as the mechanism of sensitization, three observations suggest an alternate hypothesis. First, although not a full-blown one, some sensitization did develop to the cotreatment of the kappa agonist with a low dose of QNP (Figure 1b). Second, this sensitization was the result of an increase in the peak amount of locomotor excitation without any apparent advancement in the time of the peak response or its duration (Figure 2b). Finally, in rats sensitized to QNP alone, an inhibitory response to very low doses of QNP is still evident (Lomanowska et al, 2004; Szumlinski et al, 1997; present study). Consequently, we propose a two-part hypothesis to account for sensitization to QNP: (1) some diminution of drug-depressive effects on behavior is a necessary, but not sufficient, condition for the normal development of sensitization to QNP, and (2) full-blown development of sensitization requires augmentation of the peak excitatory response and advancement of the excitatory period to temporally coincide with the drug-inhibitory interval.

It had been noted that the acute depressive effects of dopamine agonists are associated with a decline in extracellular levels of dopamine (Di Chiara et al, 1976, 1978), suggesting that a shut-down of dopamine activity may mediate behavioral suppression. The mode of action by 
which a dopamine agonist could produce this shut-down includes stimulation of somatodendritic D2 autoreceptors to reduce dopamine cell firing (Skirboll et al, 1979), stimulation of D2 autoreceptors on presynaptic terminals to inhibit dopamine release (Rouge-Pont et al, 2002), or both. Consequently, the loss of drug-depressive effects found in sensitization may reflect induction by chronic agonist treatment of autoreceptor subsensitivity (Antelman and Chiodo, 1983; Castro et al, 1985; Muller and Seeman, 1979; Richtand et al, 2001) and in particular of impulseregulating and/or release-regulating D2 autoreceptors. Indeed, a transient subsensitivity of impulse-regulating D2 autoreceptors on ventral tegmental area DA neurons had been observed following repeated treatment with QNP (Henry et al, 1998; Muscat et al, 1996). However, it is unlikely that in sensitization to QNP a similar subsensitivity exists for release-regulating D2 autoreceptors because, as found recently in a microdialysis study, the rate of diminution in extracellular dopamine to an injection of QNP was the same regardless of whether rats were sensitized to QNP or not (Koeltzow et al, 2003). In other words, the depressive effects of QNP on extracellular dopamine in the nucleus accumbens (Imperato et al, 1988) had not tolerated as a result of chronic QNP treatment, contrary to the hypothesis of D2 autoreceptor subsensitivity.

In the same study (Koeltzow et al, 2003), the authors observed that basal levels of extracellular dopamine in nucleus accumbens were lower in sensitized rats. Such a result is not surprising given that QNP can also reduce dopamine synthesis by stimulating synthesis-regulating D2 autoreceptors to inhibit tyrosine hydroxylase activity, the rate-limiting enzyme in the biosynthesis of catecholamines, (Lindgren et al, 2001, 2003a; Onali and Olianas, 1989). Presumably, with chronic QNP treatment the reduction in tyrosine hydoxylase activity would become more persistent, resulting in less available dopamine and thereby lower the basal levels of extracellular dopamine in sensitized rats.

The findings of Koeltzow et al (2003), together with the present results, provide support and elucidate a model of sensitization to QNP advanced previously (Szechtman et al, 1994b). The primary feature that distinguished the proposed model was its emphasis on an oppositional (rather than a synergistic; Daly and Waddington, 1992; Robertson and Robertson, 1986) interaction between D1 and D2 dopamine receptor systems. Drawing on findings from acute studies suggesting that D1 decreases and D2 stimulation increases locomotion (Eilam et al, 1991, 1992), it was proposed that the locomotor-depressive effects of QNP reflected a dominance of $\mathrm{D} 1$ tone during the progressive decline in dopamine release after an injection of QNP, and that the locomotor excitatory effects reflected 'pure' postsynaptic D2 stimulation without any oppositional D1 tone, a condition arising 40-60 min after QNP injection by virtue of dopamine release blockade having reached its maximum and effectively no extracellular dopamine available to stimulate D1 receptors (Imperato et al, 1988; Koeltzow et al, 2003). A plausible mechanism for the switch from preferential D1-D2 dominance is suggested by recent electrophysiological studies showing that dopamine concentration is a critical determinant of D1 vs D2 signalling: low dopamine concentration enhances neuronal currents via D1 signalling, while high dopamine concentration exerts an opposite effect on neuronal currents via a D2 signalling pathway, occluding the D1 effect (Seamans and Yang, 2004; Trantham-Davidson et al, 2004). A similar dependence on dopamine concentration may be present upon injection of QNP, shifting the balance from D1 to D2 dominance as extracellular levels of dopamine decline due to QNP-induced blockade of dopamine release, thus yielding the acute biphasic effect of QNP.

According to the proposed model, development of sensitization to QNP involves an effective reduction in D1 tone and an increase in the efficacy of D2 stimulation (Szechtman et al, 1994b). A potential mechanism of accelerated reduction in D1 tone in sensitization may be the reduced basal levels of extracellular dopamine found by Koeltzow et al (2003). To the extent that the influence of dopamine concentration on D1 vs D2 signaling (Seamans and Yang, 2004; Trantham-Davidson et al, 2004) is determined by absolute (rather than relative) neurotransmitter concentrations, an injection of QNP to sensitized rats should reduce extracellular dopamine below the critical concentration sooner, thus abbreviating the duration of D1 dominance and leading to the earlier onset of locomotor excitation found in sensitized rats. Interestingly, such a model suggests that the depressive effects of QNP are not eliminated but merely occluded by the more rapid shift to D2 dominance, a notion consistent with the fact that very low doses of QNP are still effective in inducing locomotor depression in sensitized rats (Lomanowska et al, 2004; Szumlinski et al, 1997; present study).

The above model provides a useful framework to understand the facilitating effects of kappa coadministration on sensitization to QNP, and in particular its potentiating influence on the speed and the magnitude of sensitization. Of relevance here are two particular functional aspects of stimulating kappa receptors: inhibition of dopamine release (Schoffelmeer et al, 1997; You et al, 1999) and inhibition of tyrosine hydroxylase activity (Takekoshi et al, 2000). Both of these are functionally equivalent to the proposed effects of QNP relevant for sensitization. Thus, regardless of whether their effects are additive or synergistic, coadministration of the two agonists can be expected to potentiate the depletion of extracellular dopamine and thereby the switch from D1 to D2 dominance that promotes locomotor excitation. Indeed, already upon an acute injection of the kappa agonist with QNP, the depressive effects of QNP turned into locomotor excitation (Figure 2a) and the total amount of locomotion was equivalent to what could be observed after 5-6 injections of QNP alone (Figure 1). Considering that, like D2 autoreceptors, the kappa receptors regulating dopamine release are located on presynaptic dopamine terminals (Svingos et al, 2001) (as are presumably the tyrosine hydroxylase regulating kappa receptors), the coadministration of the kappa agonist probably facilitates sensitization to QNP by a presynaptic mode of action that enhances not only the blockade of dopamine release but also the reduction in basal levels of extracellular dopamine.

However, such a presynaptic mechanism is not sufficient to account for the entire phenomenon and there probably exists also a postsynaptic mechanism on which the kappa 
agonist acts to potentiate sensitization to QNP and in particular the magnitude of sensitization. The inadequacy of only a presynaptic mechanism is evident from the observation, that in rats already sensitized to QNP, further coinjections with the kappa agonist increased even more the magnitude of locomotor sensitization to QNP (Figure 6). In rats sensitized to QNP, the relevant presynaptic changes had presumably already reached their maximum, as evidenced by loss of locomotor-depressive effects during the relative inhibitory period (Figure 3 ) and fully advanced onset of locomotor excitation (Figure 2). Consequently, kappa cotreatment in QNP-sensitized rats could have acted only postsynaptically to potentiate the peak and the duration of locomotor excitation.

In summary, the relatively independent components of sensitization to QNP may be mediated by presynaptic changes regulating the release and basal levels of dopamine, as well as by postsynaptic changes that functionally increase the efficacy of D2 receptors. Both the pre- and postsynaptic mechanisms appear modulated by stimulation of kappa receptors.

\section{Dependence of Kappa Effects on Dopamine Context}

At first glance, there may seem a contradiction between the facilitating effects of kappa agonist treatment on sensitization to QNP observed in the present study and the reports in the literature showing that kappa agonists attenuate the response to QNP (Acri et al, 2001; Izenwasser et al, 1998), as well as sensitization to cocaine (Collins et al, 2001a,b; Shippenberg et al, 2001). However, there is a crucial difference in the timing of kappa agonist injections between our study and those reports: In the present study, the kappa agonist was always coadministered together with QNP. In contrast, in the reports where inhibition had been found, the kappa agonist and QNP (or other psychostimulants) were administered sequentially; that is, several pretreatments with the kappa agonist were followed some days later with test injections of QNP (or other psychostimulants). In essence, the difference between the two procedures is that the sequential protocol investigates how plastic changes in kappa receptors impact subsequent dopamine activation, while our concurrent schedule probes how ongoing dopamine activity is influenced by kappa receptor costimulation. Thus, while in both situations the dopamine system is activated, the neural context of this activation is different: In one case it occurs on a background where the basal tone or the responsiveness of the kappa-opioid system may had been altered; in the other case it occurs on a background of a fully activated kappa receptor system. Clearly, as results show, the outcome of dopamine activation may have opposite consequences, depending on the state of kappa-opioid activation. Conversely, the same set of results also shows that the effects of kappa receptor stimulation depend on whether or not they occur in the context of dopamine activation.

The dynorphin/kappa-opioid system normally functions as a brake on dopamine activation (Shippenberg et al, 2001; Steiner and Gerfen, 1998), leading to the suggestion that targeting kappa receptors may prove useful in opposing the effects of repeated psychostimulant abuse (Shippenberg et al, 2001). However, while this notion appears reasonable with substances that are indirect dopamine agonists (cocaine, amphetamine), the phenomenon of kappa-potentiated QNP sensitization places caution on generalizing the suggestion to direct dopamine agonists. One reason for the opposite kappa effects with indirect and direct dopamine agonists relates most likely to the shift in the critical site of action from presynaptic terminals to postsynaptic neurons. With indirect dopamine agonists the primary site of action leading to increased dopamine activity are presynaptic dopamine terminals, and therefore a blockade there would prevent dopaminergic hyperactivity, consistent with the dopamine-inhibitory effects of presynaptic kappa receptors (Schoffelmeer et al, 1997; Takekoshi et al, 2000; You et al, 1999). In contrast, with direct dopamine agonists, the primary site producing dopaminergic hyperactivity are postsynaptic neurons, but kappa receptors there appear to produce functionally similar effects to dopamine receptor stimulation, according to the observed potentiation of the magnitude of QNP sensitization. Although such a neurobiological organization may complicate a pharmacological approach to drug addiction, it perhaps could be of value in treating those conditions where presynaptic dopamine function had become comprised (eg, Parkinson's disease). As shown here, dopaminergic function could be greatly stimulated by using a kappa agonist together with even a very low dose of a direct dopamine agonist.

\section{ACKNOWLEDGEMENTS}

This study was supported by an operating grant (MOP64424) from the Canadian Institutes of Health Research.

\section{REFERENCES}

Acri JB, Thompson AC, Shippenberg T (2001). Modulation of preand postsynaptic dopamine D2 receptor function by the selective kappa-opioid receptor agonist U69593. Synapse 39: 343-350.

Antelman SM, Chiodo LA (1983). Amphetamine as a stressor. In: Creese I (ed). Stimulants: Neurochemical, Behavioral and Clinical Perspectives. Raven Press: New York. pp 269-299.

Baker TB, Tiffany ST (1985). Morphine tolerance as habituation. Psychol Rev 92: 78-108.

Castro R, Abreu P, Calzadilla CH, Rodriguez M (1985). Increased or decreased locomotor response in rats following repeated administration of apomorphine depends on dosage interval. Psychopharmacology (Berl) 85: 333-339.

Centonze D, Usiello A, Gubellini P, Pisani A, Borrelli E, Bernardi G et al (2002). Dopamine D2 receptor-mediated inhibition of dopaminergic neurons in mice lacking D2L receptors. Neuropsychopharmacology 27: 723-726.

Clark D, Hjorth S, Carlsson A (1985). Dopamine receptor agonists: mechanisms underlying autoreceptor selectivity. II. Theoretical considerations. J Neural Transm 62: 171-207.

Collins SL, D’Addario C, Izenwasser S (2001a). Effects of kappaopioid receptor agonists on long-term cocaine use and dopamine neurotransmission. Eur J Pharmacol 426: 25-34.

Collins SL, Gerdes RM, D’Addario C, Izenwasser S (2001b). Kappa opioid agonists alter dopamine markers and cocaine-stimulated locomotor activity. Behav Pharmacol 12: 237-245.

Dall'Olio R, Gaggi R, Voltattorni M, Tanda O, Gandolfi O (2002). Nafadotride administration increases D1 and D1/D2 dopamine receptor mediated behaviors. Behav Pharmacol 13: 633-638.

Daly SA, Waddington JL (1992). Two directions of dopamine D1/ D2 receptor interaction in studies of behavioural regulation: a 
finding generic to four new, selective dopamine D1 receptor antagonists. Eur J Pharmacol 213: 251-258.

Di Chiara G, Porceddu ML, Vargiu L, Argiolas A, Gessa GL (1976). Evidence for dopamine receptors mediating sedation in the mouse brain. Nature 264: 564-567.

Di Chiara G, Porceddu ML, Vargiu L, Gessa GL (1978). Stimulation of 'regulatory' dopamine receptors by bromocriptine (CB-154). Pharmacology 16(Suppl 1): 135-142.

Eilam D, Clements KV, Szechtman H (1991). Differential effects of D1 and D2 dopamine agonists on stereotyped locomotion in rats. Behav Brain Res 45: 117-124.

Eilam D, Szechtman H (1989). Biphasic effect of D-2 agonist quinpirole on locomotion and movements. Eur J Pharmacol 161: 151-157.

Eilam D, Szechtman H (2005). Psychostimulant-induced behavior as an animal model of obsessive-compulsive disorder: an ethological approach to the form of compulsive rituals. CNS Spectr 10: 191-202.

Eilam D, Talangbayan H, Canaran G, Szechtman H (1992). Dopaminergic control of locomotion, mouthing, snout contact, and grooming: opposing roles of D1 and D2 receptors. Psychopharmacology (Berl) 106: 447-454.

Einat H, Einat D, Allan M, Talangbayan H, Tsafnat T, Szechtman H (1996). Associational and nonassociational mechanisms in locomotor sensitization to the dopamine agonist quinpirole. Psychopharmacology (Berl) 127: 95-101.

Harkin A, Kelly JP, Frawley J, O’Donnell JM, Leonard BE (2000). Test conditions influence the response to a drug challenge in rodents. Pharmacol Biochem Behav 65: 389-398.

Henry DJ, Hu XT, White FJ (1998). Adaptations in the mesoaccumbens dopamine system resulting from repeated administration of dopamine D1 and D2 receptor-selective agonists: relevance to cocaine sensitization. Psychopharmacology (Berl) 140: 233-242.

Hinson RE, Siegel S (1983). Anticipatory hyperexcitability and tolerance to the narcotizing effect of morphine in the rat. Behav Neurosci 97: 759-767.

Imperato A, Tanda G, Frau R, Di Chiara G (1988). Pharmacological profile of dopamine receptor agonists as studied by brain dialysis in behaving rats. J Pharmacol Exp Ther 245: 257-264.

Izenwasser S, Acri JB, Kunko PM, Shippenberg T (1998). Repeated treatment with the selective kappa opioid agonist U-69593 produces a marked depletion of dopamine D2 receptors. Synapse 30: $275-283$.

Kalivas PW, Stewart J (1991). Dopamine transmission in the initiation and expression of drug- and stress-induced sensitization of motor activity. Brain Res Rev 16: 223-244.

Kelland MD, Freeman AS, Lewitt PA, Chiodo LA (1990). Effects of (+)-4-propyl-9-hydroxynaphthoxazine on midbrain dopamine neurons: an electrophysiological study. J Pharmacol Exp Ther 255: 276-284.

Kelly MA, Rubinstein M, Phillips TJ, Lessov CN, Burkhart-Kasch S, Zhang $\mathrm{G}$ et al (1998). Locomotor activity in D2 dopamine receptordeficient mice is determined by gene dosage, genetic background, and developmental adaptations. J Neurosci 18: 3470-3479.

Kelsey JE, Carlezon Jr WA (2002). Prior experience with bromocriptine in the home cage attenuates locomotor sensitization in rats. Behav Brain Res 134: 1-8.

Khan ZU, Mrzljak L, Gutierrez A, de la CA, Goldman-Rakic PS (1998). Prominence of the dopamine D2 short isoform in dopaminergic pathways. Proc Natl Acad Sci USA 95: 7731-7736.

King GR, Xiong Z, Douglas S, Lee TH, Ellinwood EH (1999). The effects of continuous cocaine dose on the induction of behavioral tolerance and dopamine autoreceptor function. Eur J Pharmacol 376: 207-215.

Koeltzow TE, Austin JD, Vezina P (2003). Behavioral sensitization to quinpirole is not associated with increased nucleus accumbens dopamine overflow. Neuropharmacology 44: 102-110.
Koob GF, Le Moal M (1997). Drug abuse: hedonic homeostatic dysregulation. Science 278: 52-58.

Lindgren N, Usiello A, Goiny M, Haycock J, Erbs E, Greengard P et al (2003a). Distinct roles of dopamine D2L and D2S receptor isoforms in the regulation of protein phosphorylation at presynaptic and postsynaptic sites. Proc Natl Acad Sci USA 100: 4305-4309.

Lindgren N, Usiello A, Goiny M, Haycock J, Erbs E, Greengard P et al (2003b). Distinct roles of dopamine D2L and D2S receptor isoforms in the regulation of protein phosphorylation at presynaptic and postsynaptic sites. Proc Natl Acad Sci USA 100: $4305-4309$.

Lindgren N, Xu ZQ, Herrera-Marschitz M, Haycock J, Hokfelt T, Fisone $\mathrm{G}$ (2001). Dopamine $\mathrm{D}(2)$ receptors regulate tyrosine hydroxylase activity and phosphorylation at Ser40 in rat striatum. Eur J Neurosci 13: 773-780.

Lomanowska A, Gormley S, Szechtman H (2004). Presynaptic stimulation and development of locomotor sensitization to the dopamine agonist quinpirole. Pharmacol Biochem Behav 77: 617-622.

Mottola DM, Kilts JD, Lewis MM, Connery HS, Walker QD, Jones SR et al (2002). Functional selectivity of dopamine receptor agonists. I. Selective activation of postsynaptic dopamine D2 receptors linked to adenylate cyclase. J Pharmacol Exp Ther 301: 1166-1178.

Muller P, Seeman P (1979). Presynaptic subsensitivity as a possible basis for sensitization by long-term dopamine mimetics. Eur $J$ Pharmacol 55: 149-157.

Muscat R, Iravani MM, Kruk ZL (1996). The role of ventral tegmental dopamine neurons in locomotor sensitization following quinpirole or $(+)$-amphetamine: ex vivo voltammetric evidence. Neuroscience 75: 1175-1184.

Onali P, Olianas MC (1989). Involvement of adenylate cyclase inhibition in dopamine autoreceptor regulation of tyrosine hydroxylase in rat nucleus accumbens. Neurosci Lett 102: 91-96.

Pitts DK, Wang L, Kelland MD, Freeman AS, Chiodo LA (1995). Repeated stimulation of dopamine D2-like receptors: reduced responsiveness of nigrostriatal and mesoaccumbens dopamine neurons to quinpirole. J Pharmacol Exp Ther 275: 412-421.

Richtand NM, Woods SC, Berger SP, Strakowski SM (2001). D3 dopamine receptor, behavioral sensitization, and psychosis. Neurosci Biobehav Rev 25: 427-443.

Robertson GS, Robertson HA (1986). Synergistic effects of D1 and D2 dopamine agonists on turning behaviour in rats. Brain Res 384: 387-390.

Robinson TE, Becker JB (1986). Enduring changes in brain and behavior produced by chronic amphetamine administration: a review and evaluation of animal models of amphetamine psychosis. Brain Res 396: 157-198.

Rouge-Pont F, Usiello A, Benoit-Marand M, Gonon F, Piazza PV, Borrelli E (2002). Changes in extracellular dopamine induced by morphine and cocaine: crucial control by D2 receptors. J Neurosci 22: 3293-3301.

Schoffelmeer AN, Hogenboom F, Mulder AH (1997). Kappa1- and kappa2-opioid receptors mediating presynaptic inhibition of dopamine and acetylcholine release in rat neostriatum. $\mathrm{Br} J$ Pharmacol 122: 520-524.

Seamans JK, Yang CR (2004). The principal features and mechanisms of dopamine modulation in the prefrontal cortex. Prog Neurobiol 74: 1-58.

Segal DS, Schuckit MA (1983). Animal models of stimulantinduced psychosis. In: Creese I (ed). Stimulants: Neurochemical, Behavioral and Clinical Perspectives. New York: Raven Press. pp 131-167.

Segal DS, Weinberger SB, Cahill J, McCunney SJ (1980). Multiple daily amphetamine administration: behavioral and neurochemical alterations. Science 207: 905-907. 
Shilliam CS, Heidbreder CA (2003). Gradient of dopamine responsiveness to dopamine receptor agonists in subregions of the rat nucleus accumbens. Eur J Pharmacol 477: 113-122.

Shippenberg TS, Chefer VI, Zapata A, Heidbreder CA (2001). Modulation of the behavioral and neurochemical effects of psychostimulants by kappa-opioid receptor systems. Ann N Y Acad Sci 937: 50-73.

Skirboll LR, Grace AA, Bunney BS (1979). Dopamine auto- and postsynaptic receptors: electrophysiological evidence for differential sensitivity to dopamine agonists. Science 206: 80-82.

Spanagel R, Herz A, Shippenberg TS (1992). Opposing tonically active endogenous opioid systems modulate the mesolimbic dopaminergic pathway. Proc Natl Acad Sci USA 89: 2046-2050.

Starke K (1981). Presynaptic receptors. Annu Rev Pharmacol Toxicol 21: 7-30.

Starr BS, Starr MS (1986). Differential effects of dopamine D1 and D2 agonists and antagonists on velocity of movement, rearing and grooming in the mouse. Implications for the roles of D1 and D2 receptors. Neuropharmacology 25: 455-463.

Steiner H, Gerfen CR (1998). Role of dynorphin and enkephalin in the regulation of striatal output pathways and behavior. Exp Brain Res 123: 60-76.

Svingos AL, Chavkin C, Colago EE, Pickel VM (2001). Major coexpression of kappa-opioid receptors and the dopamine transporter in nucleus accumbens axonal profiles. Synapse 42: 185-192.

Szechtman H, Dai H, Mustafa S, Einat H, Sullivan RM (1994a). Effects of dose and interdose interval on locomotor sensitization to the dopamine agonist quinpirole. Pharmacol Biochem Behav 48: 921-928.

Szechtman H, Eckert MJ, Tse WS, Boersma JT, Bonura CA, McClelland JZ et al (2001). Compulsive checking behavior of quinpirole-sensitized rats as an animal model of obsessivecompulsive disorder (OCD): form and control. BMC Neurosci 2: 4.

Szechtman H, Sulis W, Eilam D (1998). Quinpirole induces compulsive checking behavior in rats: a potential animal model of obsessive-compulsive disorder (OCD). Behav Neurosci 112: $1475-1485$.

Szechtman H, Talangbayan H, Canaran G, Dai H, Eilam D (1994b). Dynamics of behavioral sensitization induced by the dopamine agonist quinpirole and a proposed central energy control mechanism (published erratum appears in Psychopharmacology (Berl) 1994 Sep;116(1):124). Psychopharmacology (Berlin) 115: 95-104.

Szumlinski KK, Allan M, Talangbayan H, Tracey A, Szechtman H (1997). Locomotor sensitization to quinpirole: environment- modulated increase in efficacy and context-dependent increase in potency. Psychopharmacology (Berlin) 134: 193-200.

Szumlinski KK, Goodwill AM, Szechtman H (2000). Locomotor sensitization to quinpirole in rats: effects of drug abstinence and sex. Psychopharmacology (Berlin) 152: 304-311.

Takekoshi K, Ishii K, Kawakami Y, Isobe K, Nakai T (2000). Kappa-opioid inhibits catecholamine biosynthesis in PC12 rat pheochromocytoma cell. FEBS Lett 477: 273-277.

Tizabi Y, Louis VA, Taylor CT, Waxman D, Culver KE, Szechtman $\mathrm{H}$ (2002). Effect of nicotine on quinpirole-induced checking behavior in rats: implications for obsessive-compulsive disorder. Biol Psychiatry 51: 164-171.

Trantham-Davidson H, Neely LC, Lavin A, Seamans JK (2004). Mechanisms underlying differential D1 versus D2 dopamine receptor regulation of inhibition in prefrontal cortex. J Neurosci 24: 10652-10659.

Usiello A, Baik JH, Rouge-Pont F, Picetti R, Dierich A, LeMeur M et al (2000). Distinct functions of the two isoforms of dopamine D2 receptors. Nature 408: 199-203.

Van Hartesveldt C, Cottrell GA, Potter T, Meyer ME (1992). Effects of intracerebral quinpirole on locomotion in rats. Eur $J$ Pharmacol 214: 27-32.

Van Hartesveldt C, Meyer ME, Potter TJ (1994). Ontogeny of biphasic locomotor effects of quinpirole. Pharmacol Biochem Behav 48: 781-786.

Vanderschuren LJ, Schoffelmeer AN, Mulder AH, de Vries TJ (1999). Dopaminergic mechanisms mediating the long-term expression of locomotor sensitization following pre-exposure to morphine or amphetamine. Psychopharmacology (Berl) 143: 244-253.

Vezina P, Giovino AA, Wise RA, Stewart J (1989). Environmentspecific cross-sensitization between the locomotor activating effects of morphine and amphetamine. Pharmacol Biochem Behav 32: 581-584.

Wang Y, Xu R, Sasaoka T, Tonegawa S, Kung MP, Sankoorikal EB (2000). Dopamine D2 long receptor-deficient mice display alterations in striatum-dependent functions. J Neurosci 20: 8305-8314.

White FJ, Wang RY (1986). Electrophysiological evidence for the existence of both D-1 and D-2 dopamine receptors in the rat nucleus accumbens. J Neurosci 6: 274-280.

Wise RA, Leeb K (1993). Psychomotor-stimulant sensitization: a unitary phenomenon? Behav Pharmacol 4: 339-349.

You ZB, Herrera-Marschitz M, Terenius L (1999). Modulation of neurotransmitter release in the basal ganglia of the rat brain by dynorphin peptides. J Pharmacol Exp Therap 290: 1307-1315. 